\title{
Characterization of Pressure Drops and Heat Transfer of Non-Newtonian Power-Law Fluid Flow Flowing in Chaotic Geometry
}

\author{
Toufik Tayebe Naas ${ }^{1 *}$, Yahia Lasbet ${ }^{1}$, Ahmed Benzaoui ${ }^{2}$ and Khaled Loubar ${ }^{3}$ \\ ${ }^{1}$ Laboratoire de Développement en Mécanique et Matériaux (LDMM), Université de Djelfa 17000, \\ Algeria \\ ${ }^{2}$ Laboratoire Thermodynamique et Systèmes Energétiques (LTSE), Université de Houari \\ Boumedien, Algeria \\ ${ }^{3}$ Ecole des Mines de Nantes. 44307 Nantes Cedex 3, France
}

Email: toufiknaas@gmail.com

\begin{abstract}
In this work, a numerical study is carried out by using CFD code to investigate a steady laminar flow of nonNewtonian power-law fluids in two geometries: complex geometry, called C-shaped, and straight channel. Cshaped geometry is a three-dimensional mini-channel of square cross-section. The chaotic flows created in this geometry enhance considerably the flow and the heat transfer performances. These performances are reported for a fixed geometry over a range of generalized Reynolds number $\left(\mathrm{Re}_{\mathrm{g}}=50-200\right)$ and power law index $(\mathrm{n}=0.5-1)$. The higher heat transfer performance is provided by the $\mathrm{C}$-shaped geometry and the lower pressure drops are obtained for the straight channel. However, the better compromise (improving heat transfer - diminution pressure drops) is for the C-shaped channel. This is evaluated via the calculation of the ratio between the Nusselt number and the Poiseuille number $\mathrm{Nu} / \mathrm{Po}$.
\end{abstract}

Keywords: Non-Newtonian power-law fluid, Laminar flow, Poiseuille number, Nusselt number, Chaotic advection.

\section{INTRODUCTION}

Enhancement of the heat transfer of non-Newtonian fluids flowing in ducts is required in many practical engineering domains [1] [2]. To achieve this goal, researchers focused on two types of geometries, curved and chaotic channels. Since the work realized by Dean [3] and [4] where he initiated theoretical studies of viscous flow, the curved pipes are widely studied numerically and experimentally. The Dean vortexes formed in these ducts have a significant effect on the pressure loss and heat transfer of non-Newtonian fluids flow [5-8]. The second alternative method is to create chaotic trajectories [9] while keeping the laminar flow that ensures the efficient stretching and folding of material lines. This type of flows is more efficient and provides better performance in terms of heat transfer [10] [11]. Kamal et al. [10] investigate numerically the enhancement of both mixing and heat transfer in a two-rod mixer for highly viscous non-Newtonian fluids. The mixer was composed of two vertical circular rods in a cylindrical tank. Chaotic flows were obtained by imposing the temporal modulations of the rotational velocities of the walls. Three different stirring protocols were chosen: nonmodulated, continuous and alternating (non-continuous). The last two protocols were able to give chaotic flow trajectories. The authors confirmed that chaotic mixing is suitable for shear thickening fluids for which it is observed a clear enhancement of the thermal mixing (heat extraction and homogenization). This is due to the increase in the apparent fluid viscosity close to the rotating walls. Lester [11] quantifies asymptotic scalar transport (temperature or concentration) by the application of a novel spectral method within both Newtonian and non-Newtonian fluids over the control parameter space of a chaotic flow, the Rotated Arc Mixer (RAM). The non-Newtonian fluid under consideration is a yield stress shear thinning fluid, which is traditional problematic traditional problematic for transport enhancement due to the existence of plug flow regions.

Our contribution in this paper is to outline and analyze the thermal and hydrodynamic behavior of power law nonNewtonian fluid in complex geometry, called in this paper Cshaped geometry, in comparison to the straight channel. The $\mathrm{C}$-shaped geometry is proposed in the first time by Beeb et al [12]. By the calculation of the Poincare section, Robin et al [13] showed the existence of chaotic trajectories within this geometry. In addition, Lasbet et al [14] characterized this geometry as a new design for the PEM fuel cell cooling system where the fluid is Newtonian (water). Their heat performance is considerably improved compared to that when the flow is regular (straight channel).

Different non-dimensional parameters are used to estimate the flow and heat characteristic: Poiseuille number, Nusselt number and the ratio $\mathrm{Nu} / \mathrm{Re}$ as function of generalized 
Reynolds number for large range of the power law index $(\mathrm{n}=$ 0.5-1). The ratio $\mathrm{Nu} / \mathrm{Po}$ characterizes the compromise between the improvement of the heat transfer and the diminution of pressure losses.

\section{MODEL AND NUMERICAL SOLUTION}

\subsection{Governing equations}

Figure 1 presents the basic elements of the two considered geometries called period(C-shaped and the straight channels).

The channel cross-section is square $(1.5 \mathrm{~cm} \times 1.5 \mathrm{~cm})$. The hydraulic diameter $D_{h}$ is $1.5 \mathrm{~cm}$. The unfolded length of one period C-shaped geometry is equal to $13.5 \mathrm{~cm}$.

The mass conservation, Navier-Stokes and energy equations, which given by equations (1), (2) and (3) respectively, are numerically solved by using the commercial CFD code Fluent $\odot$. In this study, the fluid is considered as incompressible, non-Newtonian power-law while the flow regime is steady and laminar:

$\operatorname{div} \vec{V}=0$

where $\vec{V}$ is the velocity vector.
$\vec{V} \cdot \overline{\bar{\nabla}} \vec{V}=-\frac{1}{\rho} \vec{\nabla} P+\operatorname{div} \tau$

where $(\mathrm{Pa})$ is shear stress.

$\rho c \vec{V} \cdot \vec{\nabla} T=\lambda \Delta T$

The constitutive relation between the shear stress $\tau$ (Pa) and the shear rate $\dot{\gamma}\left(\mathrm{s}^{-1}\right)$ can be described by a simple power law expression:

$\tau=k \dot{\gamma}^{n}$

where, $k\left(\mathrm{~Pa}_{\mathrm{s}} \mathrm{s}^{-1}\right)$ is power-law consistency index and $\mathrm{n}$ is the power-law index.

The apparent viscosity of the work fluid is given by:

$\mu=k \dot{\gamma}^{n-1}$

The applied boundary conditions are:

$>\quad$ at the inlet section, uniform velocity profile equal to the mean velocity.

$>$ at solid walls, no-slip conditions and a uniform wall heat surface flux.

$>$ at the outlet section, the pressure outlet condition is considered.

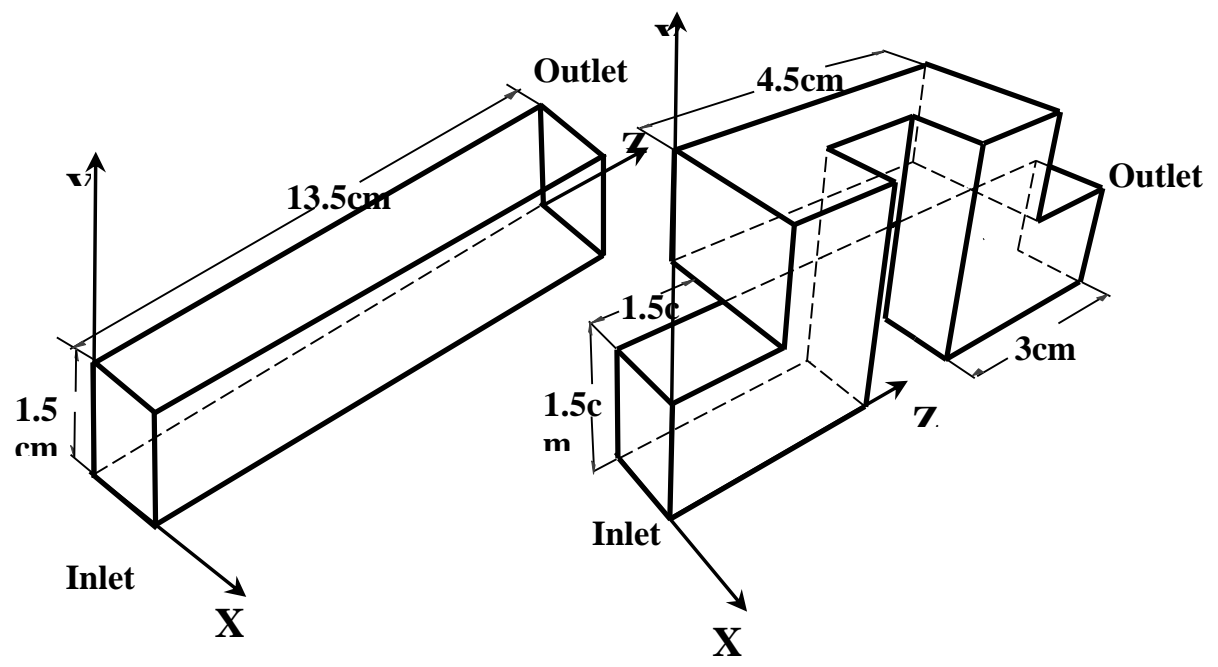

Figure 1. Schematic representation of the studied geometries: (a) straight channel, (b) C-shaped geometry.

The non-dimensional parameters that characterize the flow regime are the generalized Reynolds number $\left(\mathrm{Re}_{\mathrm{g}}\right)$ Poiseuille number $(\mathrm{Po})$ and Nusselt number $(\mathrm{Nu})$. These parameters are developed as following:

- Generalized Reynolds number

The generalized Reynolds number $\left(\mathrm{Re}_{\mathrm{g}}\right)$ for power-law fluids is defined by Metzner and Reed [15]:

$$
\operatorname{Re}_{g}=\frac{\rho U_{i}^{2-n} D_{h}^{n}}{\left[8^{n-1}\left(b^{*}+\frac{a^{*}}{n}\right)^{n} k\right]}
$$

where, $a^{*}$ and $b^{*}$ equal 0.2121 and 0.6771 respectively, for square channel and $U_{i}(\mathrm{~m} / \mathrm{s})$ is inlet velocity.
- Poiseuillenumber (Po) :

The hydrodynamic performance of all geometries is characterized by the evolution along the curvilinear coordinate $s$ of the local friction coefficient $f$, defined as:

$f=\frac{2\left(\frac{d p}{d s}\right) D_{h}}{\rho U_{i}^{2}}$

where $d p / d s$ is the local pressure gradient along the curvilinear coordinate of the channel. Because this parameter depends on the Reynolds number, it is preferable to follow the evolution of the local Poiseuille number: 


$$
P o_{\text {local }}=f \cdot \operatorname{Re}_{g}
$$

The mean Poiseuille number is calculated as:

$$
P o_{\text {mean }}=\frac{1}{L} \int_{0}^{L} P o_{\text {local }} d s
$$

where $\mathrm{s}$ is the axial coordinate.

\section{- Nusselt number:}

The local Nusselt number defined as:

$$
N u_{\text {mean }}=\frac{q_{w}}{(T b-T w)} \frac{d_{h}}{\lambda}
$$

where, $q_{w}\left(\mathrm{w} / \mathrm{m}^{2}\right)$ is the wall heat flux, $T_{b}(\mathrm{k})$ is the mean bulk temperature fluid over the cross-sectional area and $T_{w}(\mathrm{k})$ is perimeter average wall temperature.

The mean Nusselt number is given by the following equation:

$N u_{\text {mean }}=\frac{1}{L} \int_{0}^{L} N u_{\text {local }} d s$

\subsection{Numerical solution methodology}

The conservation equations for mass, momentum and energy were solved by using computational fluid dynamics (CFD) code, Fluent ${ }^{\circledR}$. The standard scheme is used for pressure discretization, and the SIMPLE scheme is employed for pressure-velocity coupling. The momentum and energy equations are solved with second-order up-wind scheme. The computations were considered to be converged once all the scaled residuals are less than $10^{-7}$ and the global imbalances, representing overall conservation don't exceed $10^{-5}$.

\subsection{Grid mesh sensibility}

To perform grid independence studies, four grids were used for simulations of non-Newtonian fluid flow in the C-shaped geometry considering a steady laminar flow, forced convection, at a generalized Reynolds number of 200and $n=$ 0.5 . These grids are ranging from 30 to 60 nodes in the $x$ and $\mathrm{y}$ direction, and from 30 to 60in the $\mathrm{z}$ direction. The Nusselt number, the Poiseuille number, velocity and temperature profiles were assessed for increasing mesh densities.

Figures 2 and 3 show the evolutions of static temperature and the axial velocity versus $\mathrm{x}$ and $\mathrm{y}$ coordinates for various grids at the center line of the outflow section. It can be seen that the temperature profiles in both $\mathrm{x}$ and $\mathrm{y}$ directions are superimposed for all mesh densities. This illustrates that the temperature profiles are not affected by the grid mesh. However, it can be observed that the velocity profiles are sensitive to the grid mesh except for the mesh densities $(50 \times 50 \times 50)$ and $(60 \times 60 \times 60)$ where no significant difference is seen. As consequence, the $(50 \times 50 \times 50)$ grid is chosen as the optimal grid mesh for the computation.

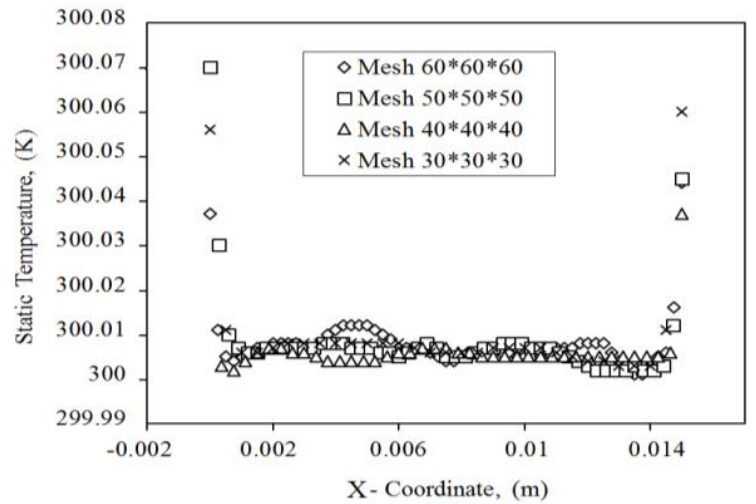

a

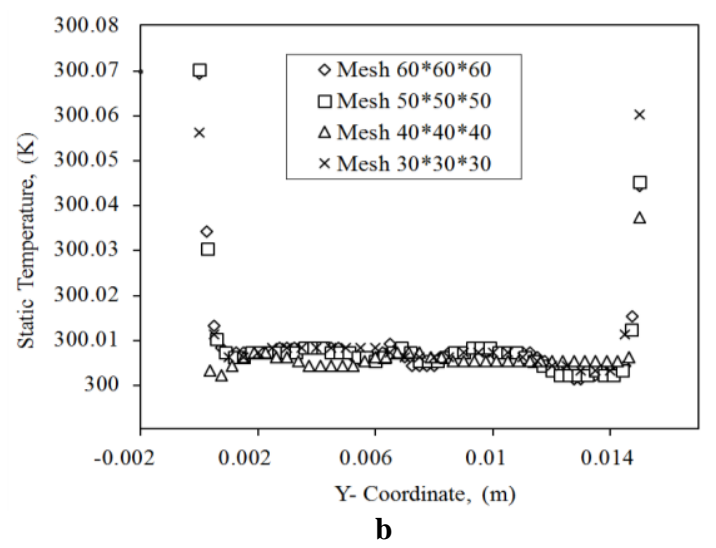

Figure 2. Temperature profiles for different mesh densities for $n=0.5$ and $\operatorname{Re}_{\mathrm{g}}=200$ at the outlet section of the C-shaped channel, (a) X-Coordinate (b) Y-coordinate

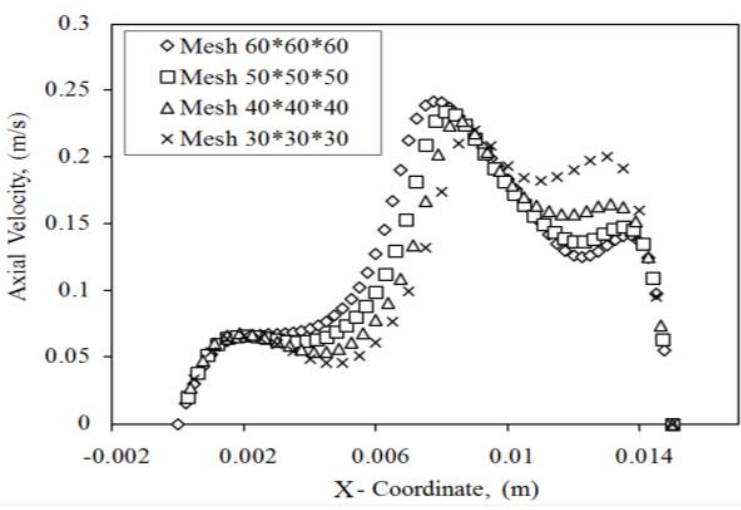

a

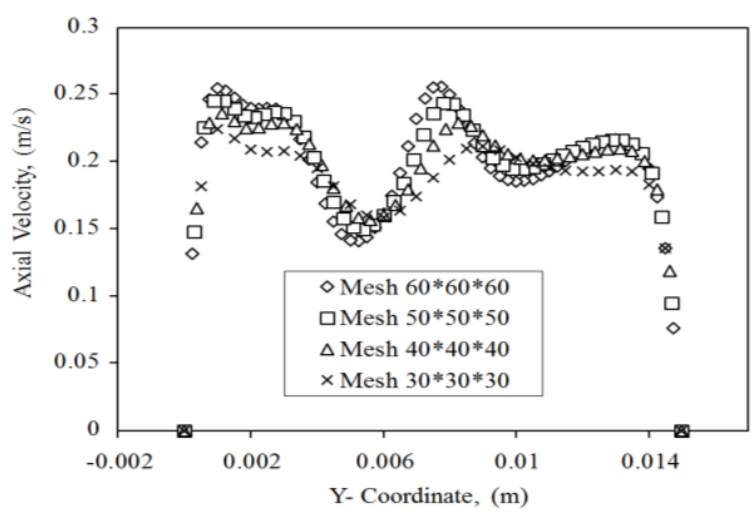

b

Figure 3. Axial-Velocity profiles for different mesh densities for $\mathrm{n}=0.5$ and $\mathrm{Re}_{\mathrm{g}}=200$ 
Table 1 presents the mean values of the Poiseuille number between inlet and outlet sections of the C-shaped geometry and the values of the local Nusselt number at the outlet section for all grid densities. It shows that the differences between the two grids mesh $(50 \times 50 \times 50)$ and $(60 \times 60 \times 60)$ of the Poiseuille and the Nusselt numbers change by less than $0.24 \%$ and $1.4 \%$ respectively. This presents another argument to select the $(50 \times 50 \times 50)$ grid mesh as the optimal mesh density for the rest of the computations.

Table 1. Mean Poiseuille number and local Nusselt number for different mesh densities for $n=0.5$ and $\mathrm{Re}_{\mathrm{g}}=200$ in the C-shaped channel

\begin{tabular}{lccll}
\hline Mesh & $P o_{\text {men }}$ & $\begin{array}{l}\text { Error/ } \\
P o_{\text {mean }}\end{array}$ & $\mathrm{Nu}_{\text {local }}$ & $\begin{array}{l}\text { Error/ } \\
\mathrm{Nu}_{\text {mean }}\end{array}$ \\
\cline { 2 - 5 } $30 \times 30 \times 30$ & 218.270 & $0.13 \%$ & 41.741 & $13.56 \%$ \\
$40 * 40 * 40$ & 219.270 & $-0.32 \%$ & 45.8307 & $5.09 \%$ \\
$50 * 50 * 50$ & 219.099 & $-0.24 \%$ & 47.6098 & $1.41 \%$ \\
$60 * 60 * 60$ & 218.561 & $0.00 \%$ & 48.2904 & $0.00 \%$ \\
\hline
\end{tabular}

\section{VALIDATION}

In this section, in order to check the reliability and the precision of the CFD computation, a comparison with other results provided in the literature is carried out. A fully developing laminar steady flow of non-Newtonian power-law fluid in straight channel with square cross section is considered.

Tables 2 and 3 present, respectively, a comparison of the values of the Poiseuille number and the Nusselt number obtained in the present study and those provided in the literature for large range of a power-law index $(n=0.3-1)$. The numerical values barely differ from the case of the theoretical values where the maximum difference is less than $0.5 \%$. These values are in fair agreement and the comparison is satisfactory and reveals a very good concordance.

Table 2. Poiseuille number, Po, of fully developed laminar flow in square straight channel for different power-law index $(\mathrm{n}=0.3-1)$

\begin{tabular}{lllllllll}
\hline $\mathrm{n}$ & 1 & 0.9 & 0.8 & 0.7 & 0.6 & 0.5 & 0.4 & 0.3 \\
\cline { 2 - 8 } Present work & 56.90 & 47.47 & 39.32 & 33.00 & 27.52 & 22.90 & 18.99 & 15.66 \\
Wheeler and Wissler [16] & 56.92 & 47.53 & 39.67 & 33.07 & 27.54 & 22.89 & 18.97 & 15.65 \\
Seppo [17] & 56.90 & 47.52 & 39.65 & 33.06 & 27.53 & 22.88 & 18.96 & 15.64 \\
Simsoo et al [18] & 56.90 & 47.89 & 40.29 & 33.89 & 28.49 & 23.91 & 20.01 & - \\
Kozicki et al [19] & 56.91 & 47.88 & 40.26 & 33.82 & 28.37 & 23.75 & 19.82 & - \\
Sayed-Ahmed [20] & 56.90 & - & - & - & - & 22.88 & - & - \\
Error (\%)/ [17] & 0.007 & 0.09 & 0.82 & 0.17 & 0.05 & -0.06 & -0.14 & -0.14 \\
\hline
\end{tabular}

Table 3. Nusselt number of fully developed laminar flow in square straight channel for different power-law index $(\mathrm{n}=0.5-1)$

\begin{tabular}{lllllll}
\hline $\mathrm{n}$ & 1 & 0.9 & 0.8 & 0.7 & 0.6 & 0.5 \\
\cline { 2 - 6 } Present work & 3.0704 & 3.1140 & 3.1463 & 3.1832 & 3.228 & 3.2818 \\
Wheeler and Wissler [16] & 3.0950 & 3.106 & 3.135 & 3.171 & 3.216 & 3.274 \\
Error $(\%) /[16]$ & 0.2407 & -0.2580 & -0.3607 & -0.3869 & -0.3736 & -0.2386 \\
\hline
\end{tabular}

\section{DISCUSSION AND RESULTS}

In this section, the flow and heat transfer characteristics for a power law non Newtonian fluid are studied in detail based on the numerical solution. The flow structure is the main contribution factor which affects the flow and heat transfer performances in the geometries. Furthermore, these performances are a complex function of generalized Reynolds number and power law index. As known, the improvement of the heat transfer performance is accompanied with an augmentation of the pressure drop penalty. According to above, it is interesting to measure the energetic efficiency of the considered geometries. This efficiency illustrates the compromise between heat transfer and pressure losses. Three main parameters are considered in order to achieve the focused goals: Poiseuille number (Po) for the flow characteristics, Nusselt number $(\mathrm{Nu})$ for the heat characteristics and the ratio $(\mathrm{Po} / \mathrm{Nu})$ for the efficiency measurement. These parameters are evaluated for generalized number and power law index ranging from 50 to 200 and 0.5 to 1 respectively.

\subsection{Flow characteristics}

Figure 6 and 7 show the evolutions of the axial velocity profiles with $\mathrm{x}$ and $\mathrm{y}$ coordinates at the center line of the straight channel outlet section for power law non-Newtonian fluid for two generalized Reynolds number 50 and 150. The power-law index varies from 0.5 to 1 . The profiles of the velocity are symmetric and parabolic. The maximum velocity is located in the center of the cross section and it increases considerably with the increase of the power law index. It can be seen clearly that, in the straight channel, particles Pathlines released from the inlet section are parallel resulting in no motion of the fluid particles in the transverse direction of the flow, see figures 4 . In addition, figure 5 displays that there is 
no secondary flows appeared in the outlet cross section. So, the momentum transfer is limited only to the molecular

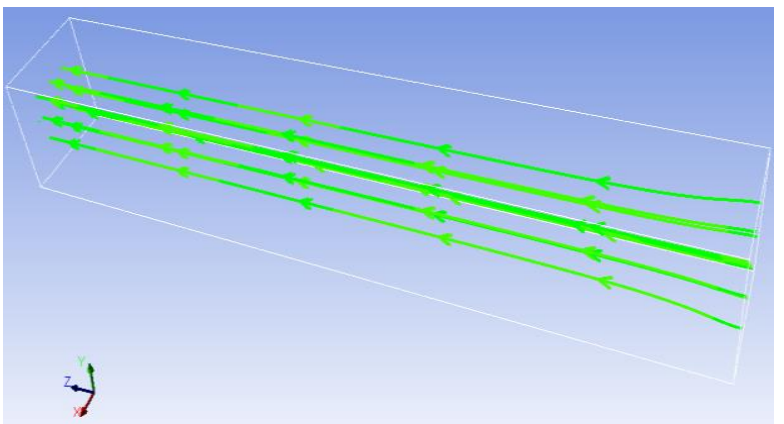

$\operatorname{Re}_{\mathrm{g}}=50 \mathrm{n}=0.5$

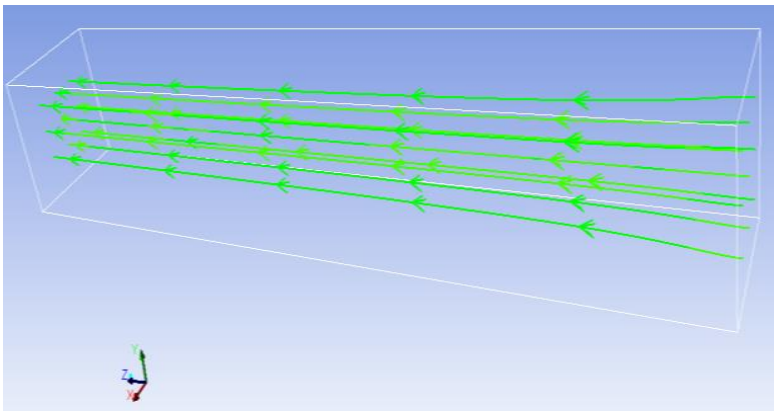

$\operatorname{Re}_{\mathrm{g}}=150 \mathrm{n}=0.5$ diffusion mode for all cases of the power law index $n$.

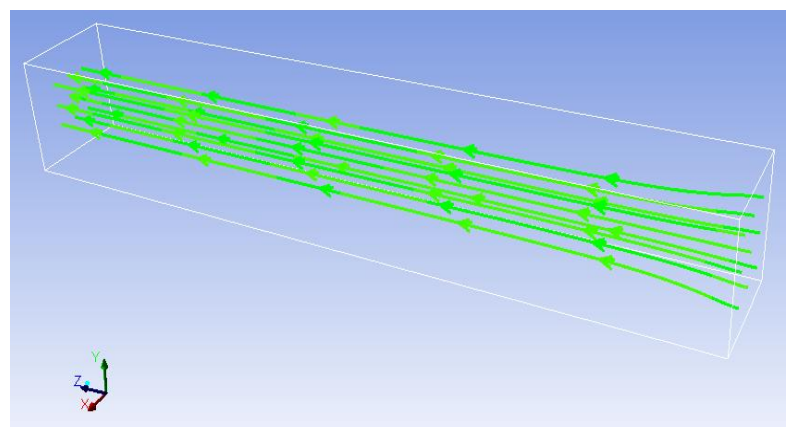

$\mathrm{Re}_{\mathrm{g}}=50 \mathrm{n}=1$

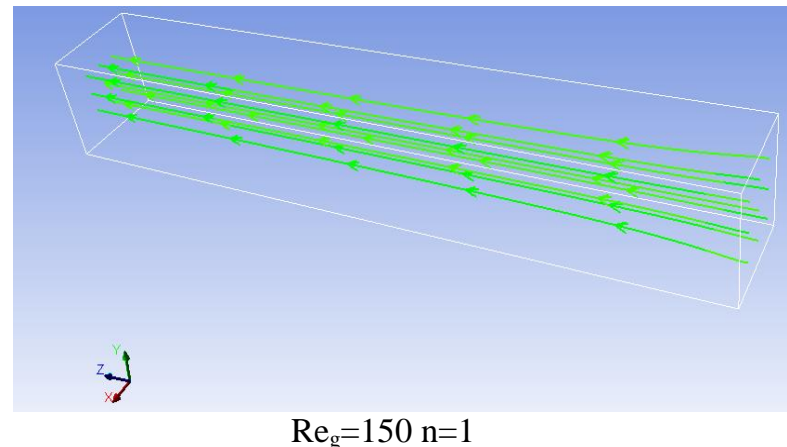

$\operatorname{Re}_{\mathrm{g}}=150 \mathrm{n}=1$

Figure 4. Particle Pathlines released from the inlet section

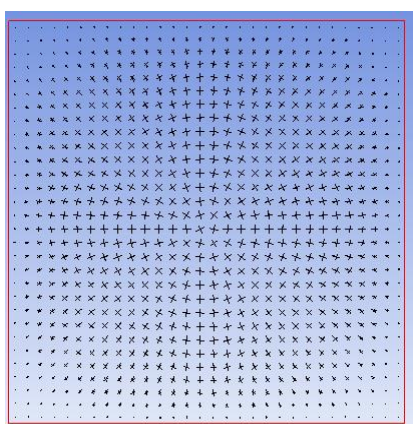

$\mathrm{Re}_{\mathrm{g}}=50 \mathrm{n}=0.5$

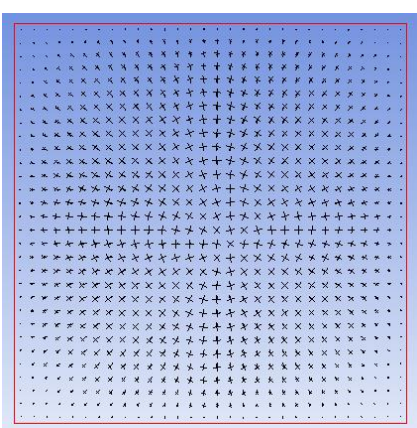

$\operatorname{Re}_{\mathrm{g}}=50 \mathrm{n}=1$

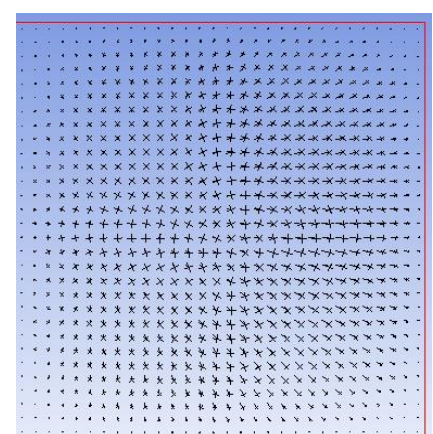

$\operatorname{Re}_{\mathrm{g}}=150 \mathrm{n}=0.5$

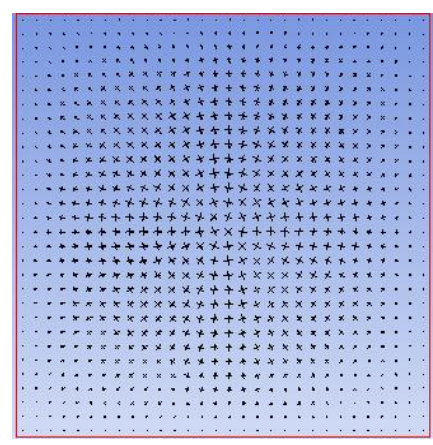

$\mathrm{Re}_{\mathrm{g}}=150 \mathrm{n}=1$

Figure 5. Velocity vectors distribution in outlet cross section

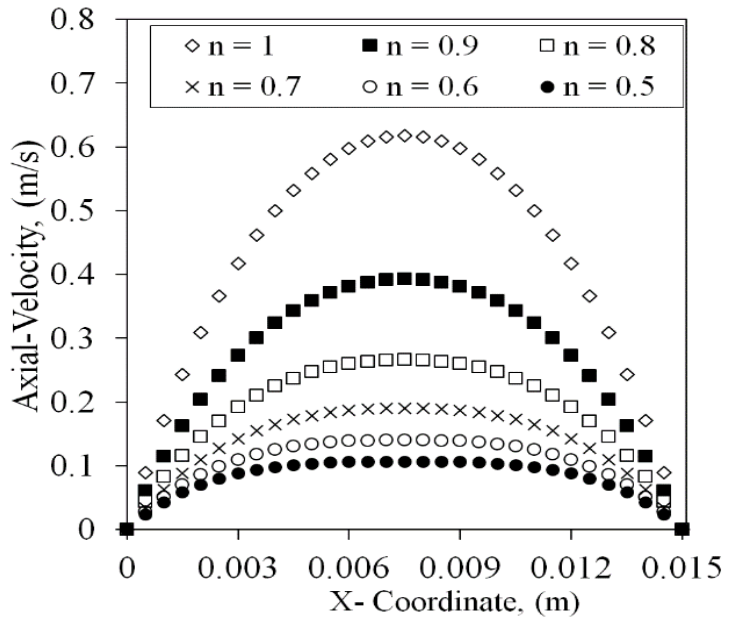

a

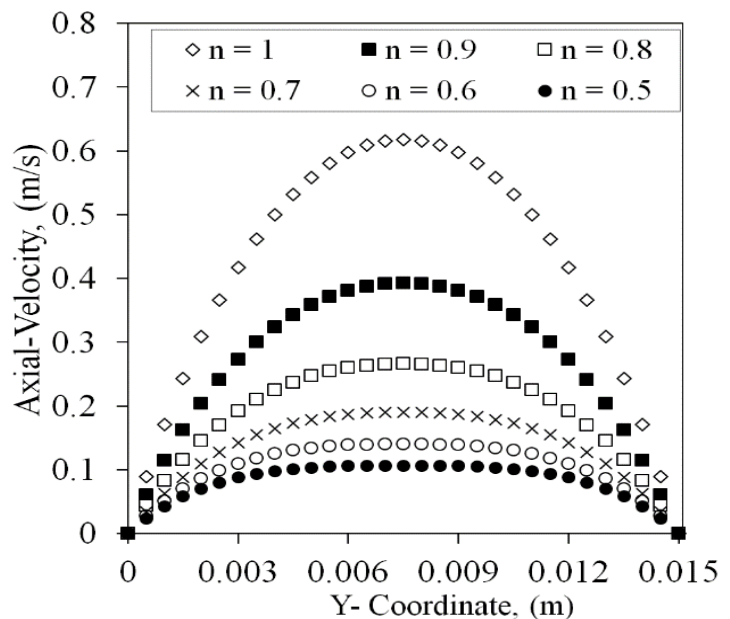

b

Figure 6. Axial velocity profiles at the outlet section of the straight channel for $\mathrm{Re}_{\mathrm{g}}=50$, (a) X-Coordinate and (b) $\mathrm{Y}$ Coordinate 

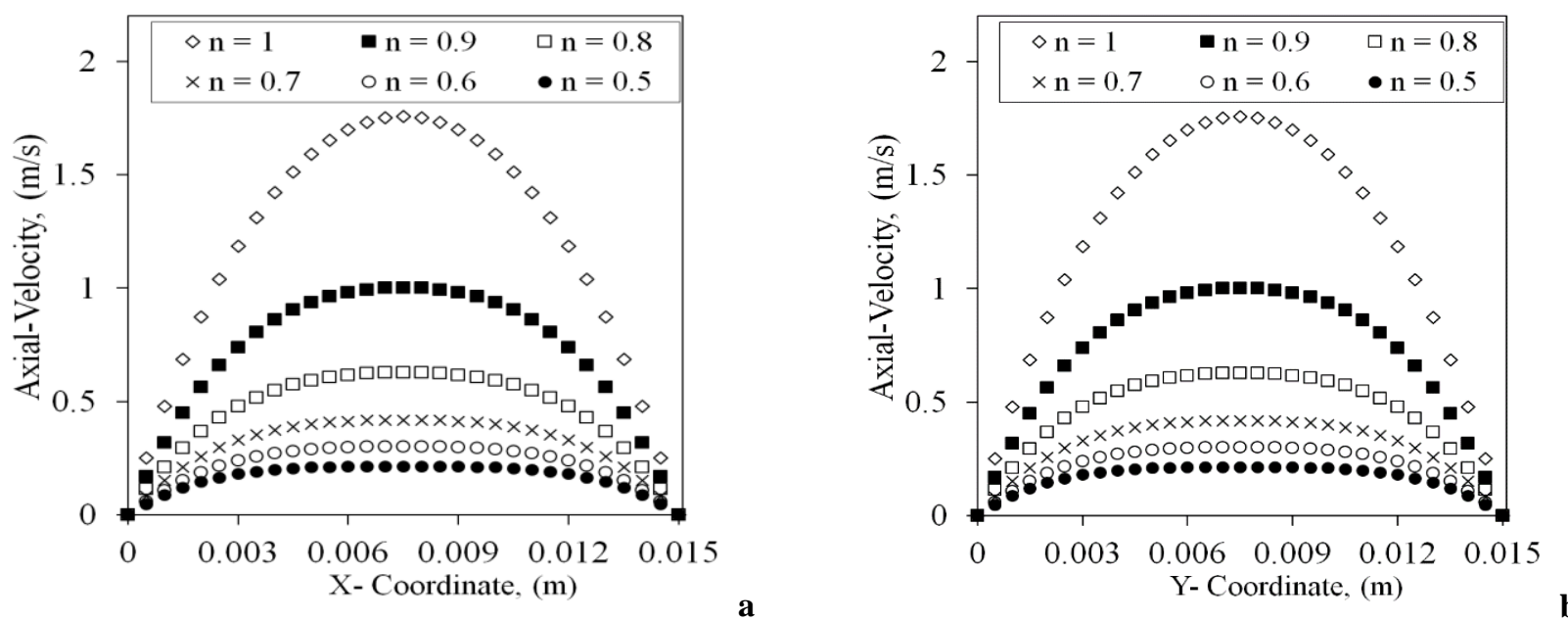

Figure 7. Axial velocity profiles at the outlet section of the straight channel for $\operatorname{Re}_{g}=150$, (a) $\mathrm{X}$ Coordinate and (b) Y-Coordinate

Figure 8 and 9 show the evolutions of the axial velocity with $\mathrm{x}$ and $\mathrm{y}$ coordinate at the center line of the outlet section in the $\mathrm{C}$-shaped geometry for power law non-Newtonian fluid for two generalized Reynolds number 50 and 150.The velocity distributions within the channel highlight the flow complexity where the symmetric nature of the velocity profile is disrupted under the effect of the secondary flows. The velocity profiles in the central core region are lower compared to that in the straight channel. The location of the maximum velocity point in this type of geometry is of interest. One can gain the general idea about the secondary flow pattern and the intensity of secondary flow. The results show clearly that the effect of the secondary flows is to shift the location of the maximum value toward the walls. In addition, the maximum value increases as the value of the power law index increases.

Besides, the evolutions of the local and the mean Poiseuille numbers in the interest of channels are examined. This parameter depends strongly on the nature of the kinematic trajectories of fluid particles in the flow. Figure 10 presents the evolutions of the local Poiseuille number with the curvilinear coordinate for a generalized Reynolds number equal to 100 and for two values of the power law index 0.5 and 1 in three periods of the straight and $\mathrm{C}$-shaped channels.

Because the flow is regular in the straight channel, the local Poiseuille number decreases rapidly at the entrance of the channel as function of the curvilinear coordinate and it tends towards an asymptotic value once the flow is established. This value increases with the power law index $n$. In the $C$ shaped geometry and from the second period, the variation of the local Poiseuille number is periodic. This is explained by the fact that the velocity field is itself periodic (figure 11). The flow is enough disrupted due to the existence of the geometrical perturbations which prevents the establishment of the boundary layer. This phenomen on increases strongly the pressure drop. Figure 12 presents the evolution of the mean Poiseuille number with generalized Reynolds number for the two considered geometries and for power law index ranging from 0.5 to 1 .

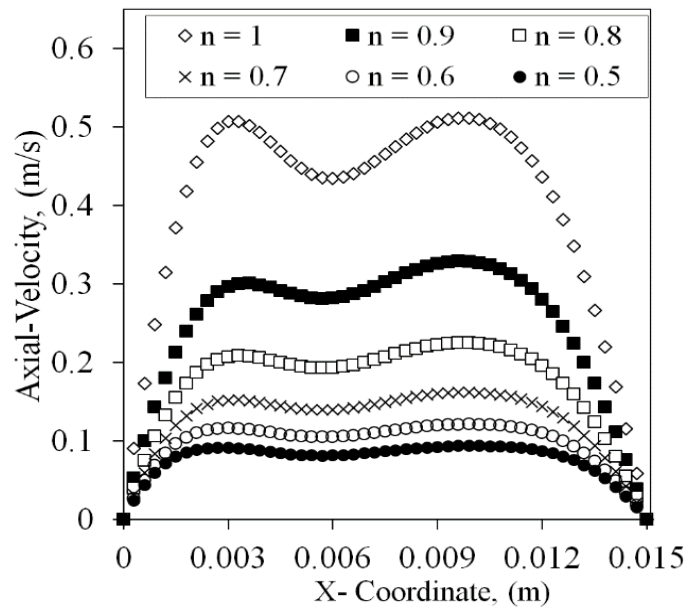

a

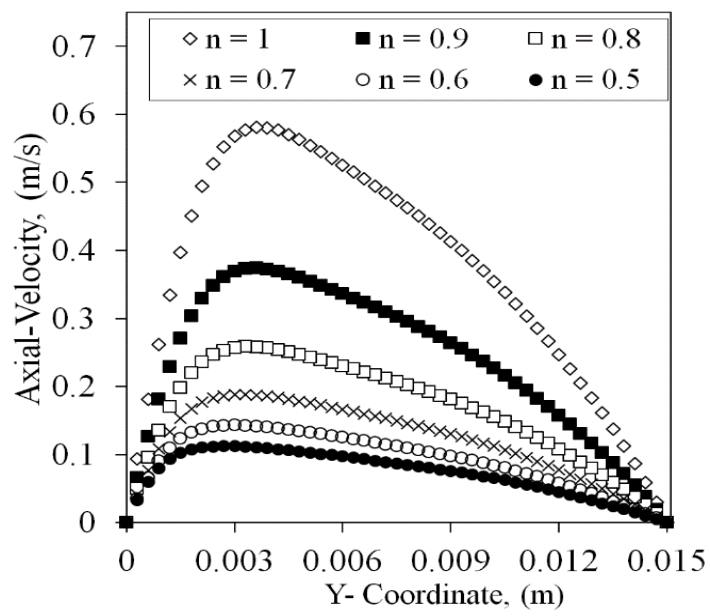

b

Figure 8. Axial velocity profiles at the outlet section of the C-shaped channel for $\mathrm{Re}_{\mathrm{g}}=50$, (a) $\mathrm{x}$-coordinate and (b) y-coordinate 


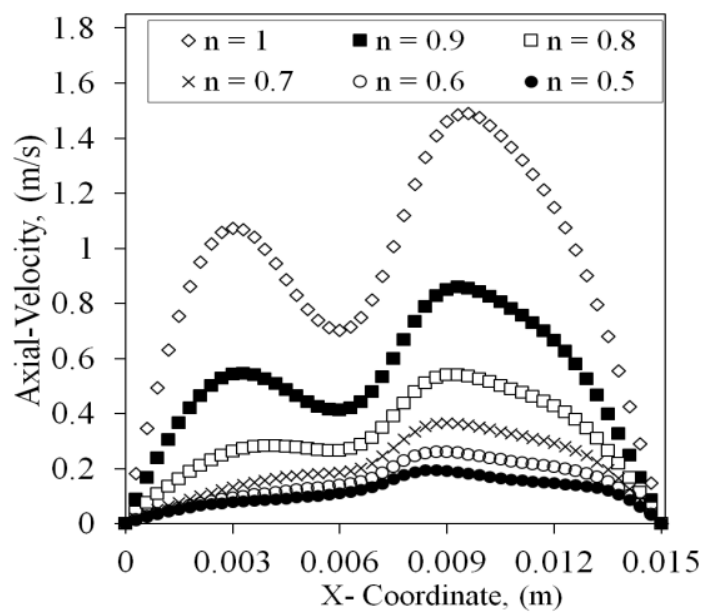

a

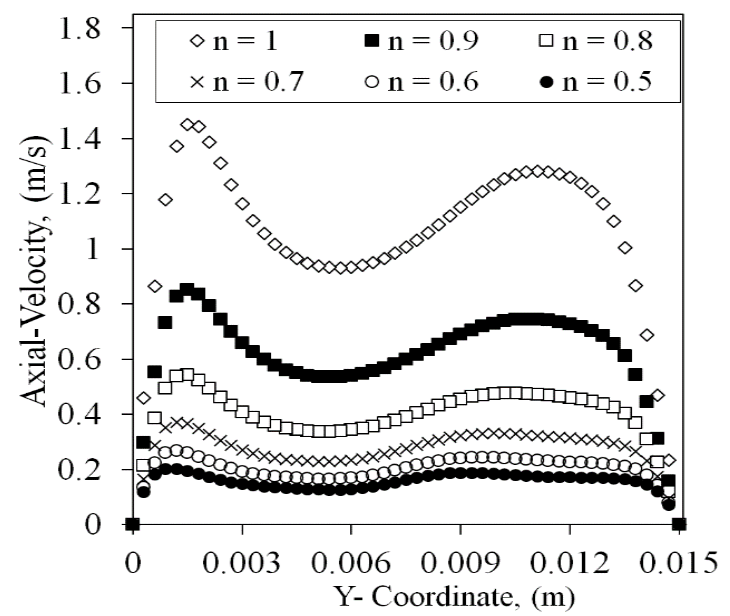

b

Figure 9. Axial velocity profiles at the outlet section of the C-shaped channel for $\operatorname{Re}_{\mathrm{g}}=150$, (a) $\mathrm{x}$-coordinate and (b) $\mathrm{y}$ coordinate

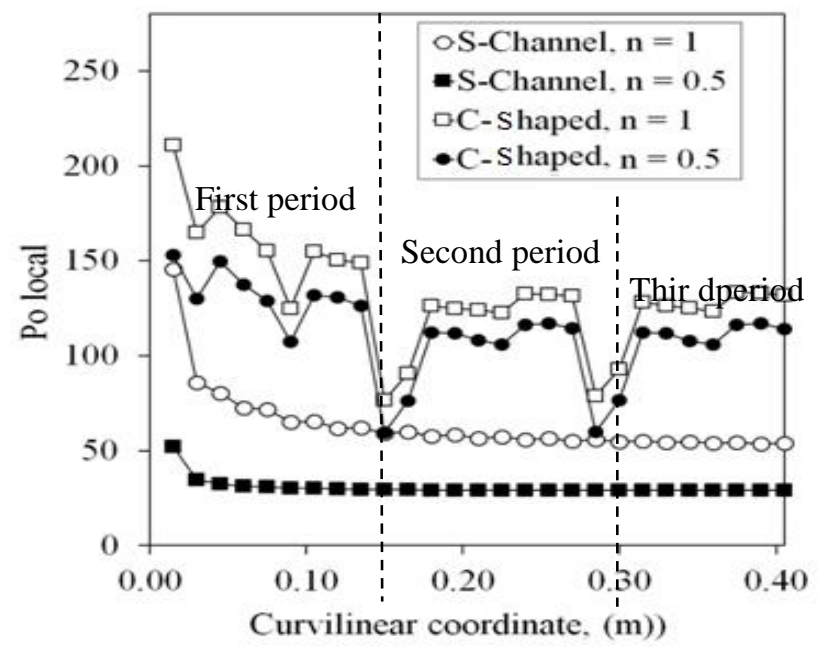

Figure 10. Evolutions of the local Poiseuille number with the curvilinear coordinate for the two geometries for a power law index of 0.5 and $1\left(\operatorname{Re}_{\mathrm{g}}=100\right)$
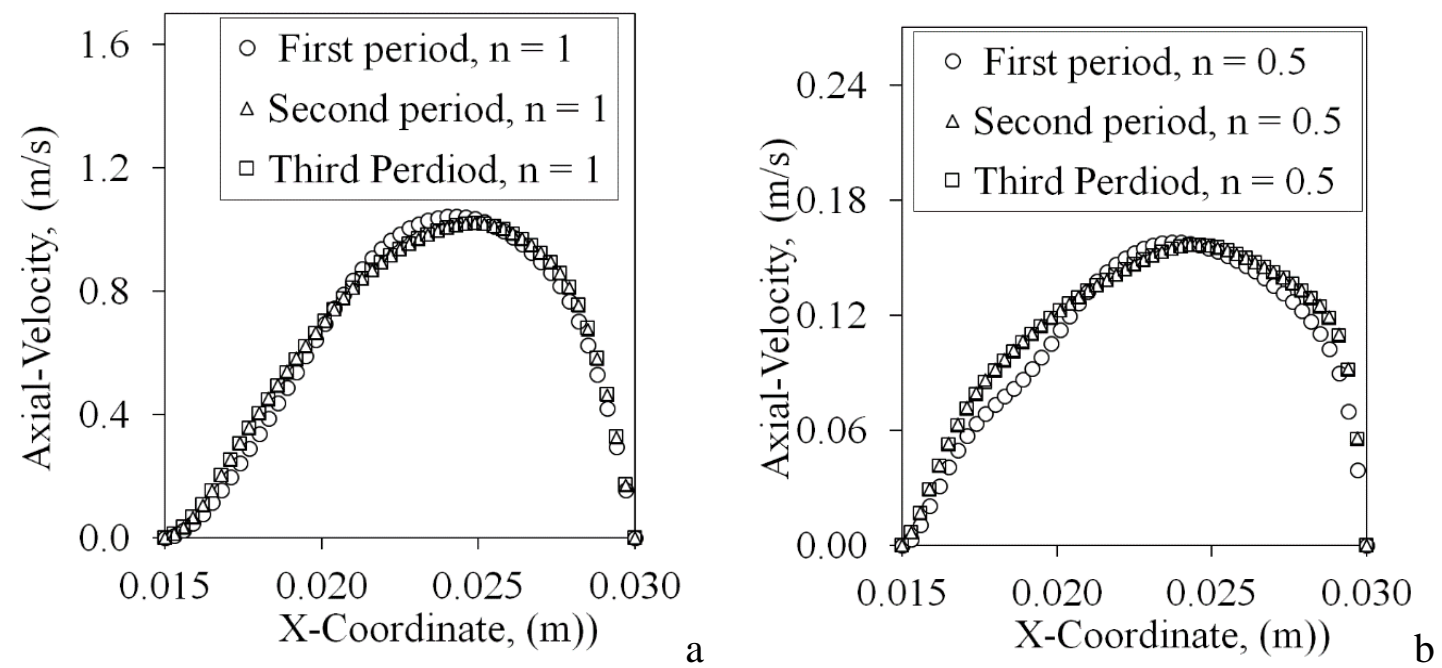

Figure 11. Axial-Velocity profiles in the C-shaped channel at the middle of each period as function of $x$ coordinate, (a) $n=1$, (b) $n=0.5$ 


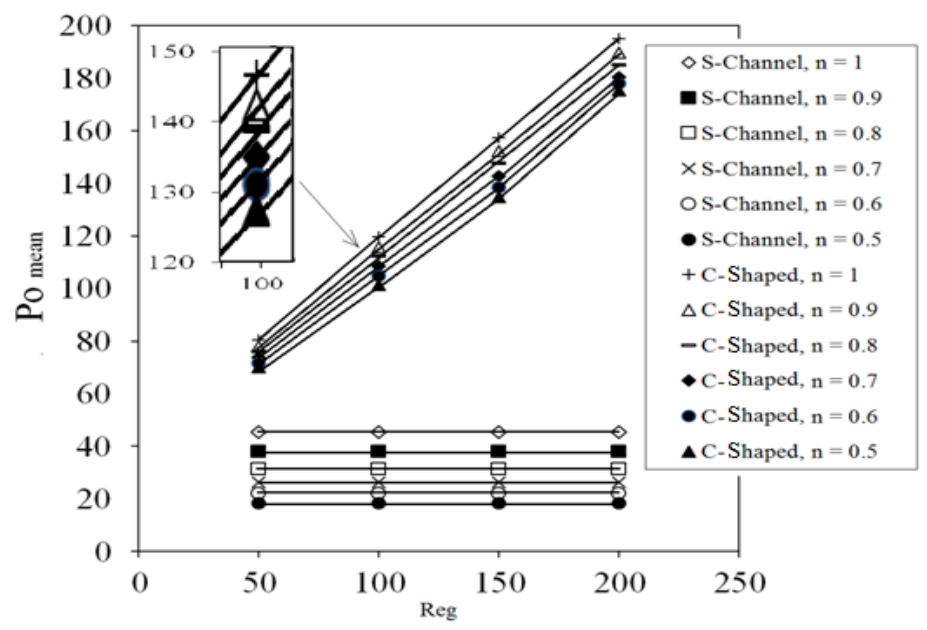

Figure 12. Evolution of the mean Poiseuille number with generalized Reynolds number in straight (Schannel) and C-shaped channels

In the straight channel and when the flow regime is established, the mean Poiseuille number keep a constant value whatever the generalized Reynolds number for a given value of power law index $n$. This parameter (Po mean) increases with the growth of the power law index.As mentioned to above, the pressure drops are influenced by the intense secondary flows and accentuated with the increase of the generalized number and the power law index. So, the mean Poiseuille number is very significant in the $\mathrm{C}$-shaped than that calculated in the straight channel.

\subsection{Heat characteristics}

Figure 13 presents the evolutions of the local Nusselt number with the curvilinear coordinate in the interest geometries for two values of the power law index 0.5 and 1 and for a generalized number equal to 100.In the entrance length of the straight channel, the local Nusselt number decreases strongly to reach an asymptotic value which depends on the power law index. However, in the C-shaped geometry, the chaotic behavior exhibits a marked influence on heat transfer distributions in the system. Due to the continuous effect of the boundary layer destruction, the local Nusselt number evolves periodically with the curvilinear coordinate which allowed us to make the computation in one period. Consequently, the thermal boundary layer in the chaotic tube became thin and the heat transfer is very sensitive to temperature changes between the wall temperature and the mean bulk temperature. The maximum variation of the local Nusselt number is very considerable and it is around 40.In order to compare the heat performances between the two geometries, the variation of the mean Nusselt number as function of generalized Reynolds number for several power law index values ranging from 0.5 to 1 is estimated (figure 14).

In the straight channel, the mean Nusselt number is independent of the generalized Reynolds number and keeps a constant value which increases with the power law index value $n$.

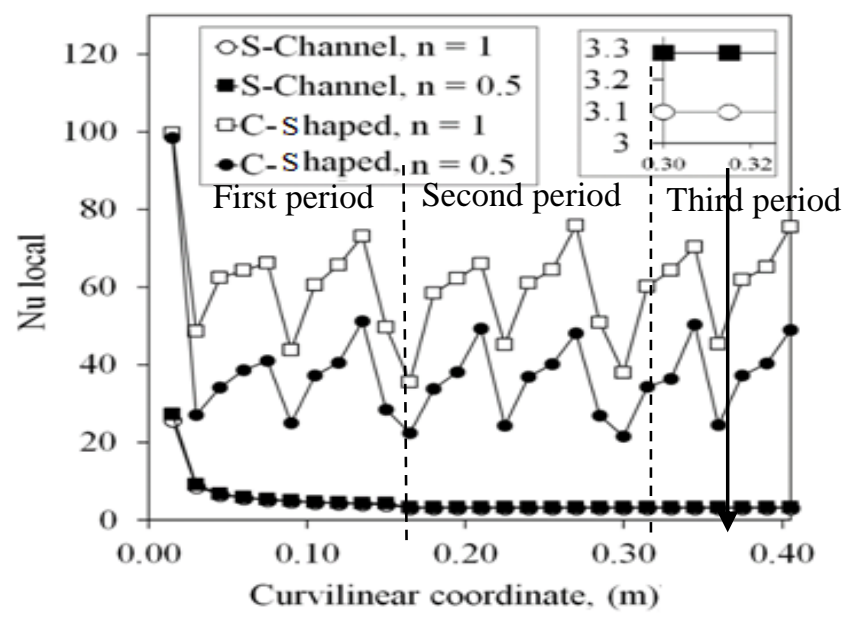

Figure 13. Evolutions of the local Nusselt number with the curvilinear coordinate in the two geometries for two values of the power law index 0.5 and $1\left(\operatorname{Re}_{\mathrm{g}}=100\right)$ 


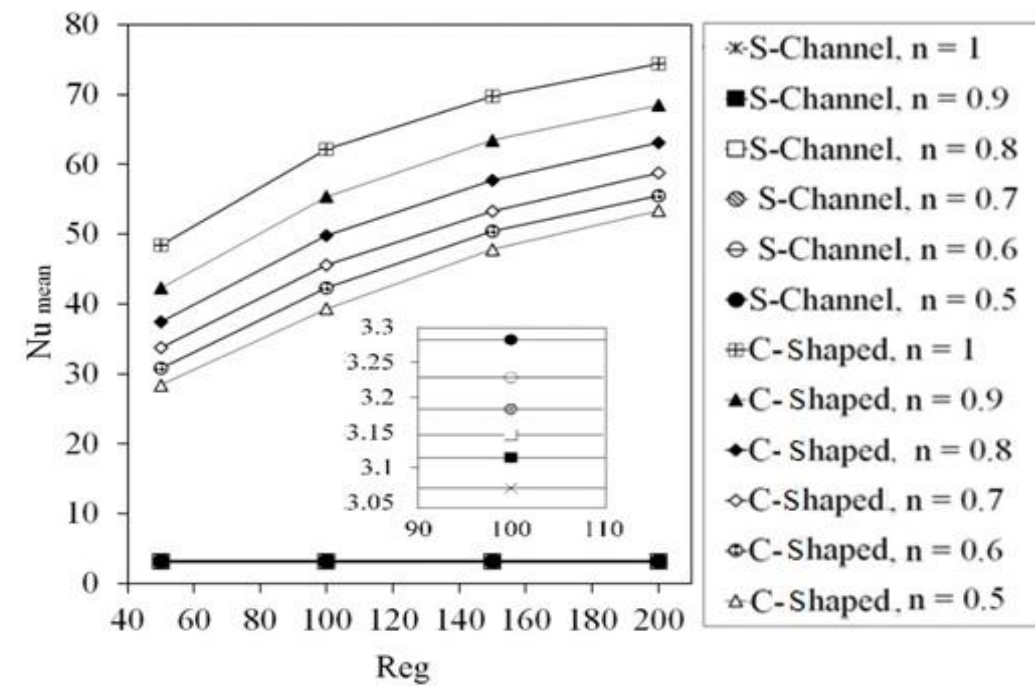

Figure 14. Evolution of the mean Nusselt number with generalized Reynolds number in straight and C-shaped channels Power law index $(\mathrm{n}=1$ to 0.5$)$

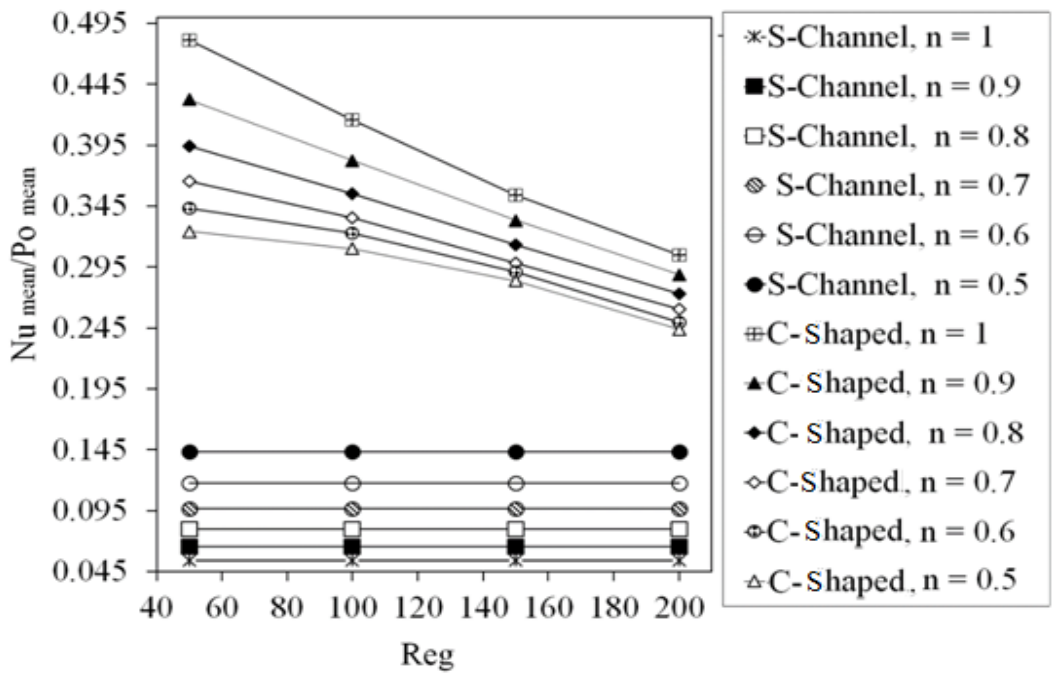

Figure.15. Evolution of the ratio of the Poiseuille number to the Nusselt number with different Power law index for straight channel and C-shaped geometry

This is due to the effect of the chaotic kinematics of the particles. With a view to examine the increase of heat transfer rate rather than the decrease of pressure drop, we present on the figure 15 the evolutions of the ratio $\mathrm{Nu}_{\text {mean }} / \mathrm{Po}_{\text {mean }}$ with the generalized Reynolds number for the power law index values. When this ratio is high, the compromise (improving heat transfer- diminution pressure losses) is the best. In the straight channel, this parameter has a constant value for a given power law index and is lower when $\mathrm{n}=1$.

However, in the $\mathrm{C}$-shaped geometry, the ratio $\mathrm{Nu} / \mathrm{Po}$ becomes higher with the increase of the power law index but it decreases with the generalized Reynolds number. As conclusion, the compromise (improving heat transferdiminution pressure losses) provided by the C-shaped is very significant in comparison with that calculated in the straight channel.

\section{CONCLUSIONS}

In this work, numerical simulations were performed by using CFD code in order to study flow characteristics of the
non-Newtonian power law fluid in two geometries, C-shaped and straight channels, in terms of heat transfer and fluid flow.

This paper outlines the evolutions of the Nusselt number and the Poiseuille number with generalized Reynolds number and with the power law index ranging from 0.5 to 1.It was observed that the local friction factor and Nusselt number straches and folded as the axial distance increases. The chaotic configuration displays a heat transfer enhancement in terms of the mean Nusselt number compared to the straight channel, however the pressure drop in this geometry increases (high Poiseuille number) for all examined Reynolds number. Despite this, the ratio of the Nusselt number to the Poiseuille number is higher in the C-shaped geometry, showing that the heat transfer enhancement is important than the pressure loss increase. The study of thermal mixing in the $\mathrm{C}$-shaped geometry of the Non-Newtonian fluids is in progress.

\section{REFERENCES}

[1] Nazmeev, Y. G., "Intensification of convective heat exchange by ribbon swirlers in the flow of an 
ominously viscous liquid sinpipes", J. Eng Phys., vol. 37, pp. 910-913, 1979. DOI: 10.1007/BF00861442.

[2] A. G. Patil, "Laminar flow heat transfer and pressure drop characteristics of power-law fluids inside tubes with varying width twisted tape inserts", J. Heat Transfer., vol. 122, pp. 143-149, 2000. DOI: $10.1115 / 1.521448$.

[3] Dean, W. R., "Note on the notion of fluid in a curved pipe", Phil. Mag., vol.7, no. 4, pp. 208-223, 1927. DOI: $10.1080 / 14786440708564324$.

[4] Dean, W. R., "The stream-line motion of fluid in a curved pipe", Philos. Mag., vol. 7, no. 5, pp. 673-695, 1928. DOI: $10.1080 / 14786440408564513$.

[5] Zabielski, L. and Mestel A. J., "Unsteady blood flow in a helically symmetrical pipe", J. of Fluid Mech., Vol. 370, pp. 321-345, 1998 . DOI: 10.1017/S0022112098001992.

[6] Ali, S. S, Kayvan, S and Mehrdad, R., "On the use of lattice Boltzmann model for simulating dean flow of non-Newtonian fluids in curved square ducts", Com Nonlinear Sci Numer Simulat., vol. 17, pp. 4250-4260, 2012. DOI: $10.1016 /$ j.cnsns.2012.03.026.

[7] Pimenta, T. A. and Campos. J.B.L.M., "Heat transfer coefficients from Newtonian and non-Newtonian fluids flowing in laminar regime in a helical coil", Int J. Heat and Mass Trans., vol. 58, pp. 676-690, 2013. DOI: 10.1016/j.ijheatmasstransfer.2012.10.078.

[8] Norouzi, M., Davoodi M and Anwar Bég O., "An analytical solution for convective heat transfer of viscoelastic flows in rotating curved pipes", Int J. Ther Sci., vol. 90, pp. 90-111, 2015. DOI: 10.1016/j.ijthermalsci.2014.11.025.

[9] Aref, H., "Stirring by chaotic advection", J. Fluid Mech., vol. 143, pp. 1-21, 1984. DOI: $10.1017 / \mathrm{S} 0022112084001233$.

[10] Kamal, E. O. and Guer Y. L, "Thermal chaotic mixing of power-law fluids in a mixer with alternately rotating walls", J. Non-Newt Fluid Mech., vol. 165, pp. 641651, 2010. DOI: 10.1016/j.jnnfm.2010.03.004.

[11] Lester, D. R., Rudman M. and Metcalfe G., "Low Reynolds number scalar transport enhancement in viscous and non-Newtonian fluids", Int J. Heat and Mass Tran., vol. 52, pp. 655-664, 2009. DOI: $\underline{10.1016 / j . i j h e a t m a s s t r a n s f e r .2008 .06 .039}$.
[12] Beebe, D. J., Adrian, R. J., Olsen, M. G., Stremler, M. A., Aref, H., and Jo, B., "Passive mixing in microchannels: Fabrication and flow experiments", $J$. Mécanique et Industries., vol. 2, pp. 343-348, 2001. DOI: $\underline{\mathrm{S} 1057-7157(00) 04860-5}$.

[13] Liu, R. H, Stremler, M. A, Sharp, K. V, Olsen, M. G, Santiago, J. G, Adrian, R. J, Aref, H. and Beebe, D. J., "Passive mixing in a three-dimensional serpentine microchannel", J. Microelectromech Sys., vol. 9, pp. 190-197, 2000. DOI: 10.1109/84.846699.

[14] Yahia, L., Bruno, A., Cathy, C. and Hassan, P., "Thermal and hydrodynamic performances of chaotic mini-channel: Application to the fuel cell cooling", $J$. Heat Tran Eng., vol. 28, no. 8, pp. 795-803, 2007. DOI: $10.1080 / 01457630701328908$.

[15] Metzner, A. B. and Reed, J. C., "Flow of nonNewtonian fluids correlation of the laminar transition, and turbulent-flow regions", AIChE J., no. 1, vol. 434, 1955. DOI: $10.1002 /$ aic.690010409.

[16] Wheeler, J. A. and Wissler, E. H., "The friction factorReynolds number relation for a steady flow of pseudoplastic fluids through rectangular ducts", Aiche $J$,. vol. 11 , pp. 07-216, 1966. DOI: 10.1002/aic.690110208.

[17] Seppo, S., "Finite-element analysis of fully developed laminar flow of power-law non-Newtonian fluid in a rectangular duct", Int. Corant Heat Mass Transfer., vol. 22, no. 4, pp, 549-557, 1995. DOI: 10.1016/07351933(95)00040-6.

[18] Simsoo, P., Irvine, T. F. and Capobianchi, Jr. M., "Experimental and numerical study of friction factor for a modified power law fluid in a rectangular duct", J. Exp Ther and Fluid Sci., vol. 9, pp. 61-68, 1994. DOI: $10.1016 / 0894-1777(94) 90009-4$.

[19] Kozieki, W., Chou, C. H., Tiu, C., "Non-Newtonian flow in ducts of arbitrary cross-sectional shape", $J$. Che. Engrg Sci., vol. 665, no. 21, 1966. DOI: 10.1016/0009-2509(66)80016-7.

[20] Sayed-Ahmed, M. E., "Laminar heat transfer for thermally developing flow of a Herschel-Bulkley fluid in a square duct", Int. Comm. Heat Transfer., vol. 27, no. 7, pp. 1013-1024, 2000. DOI: 10.1016/S07351933(00)00181-0. 